where an eye-piece must be placed. At that point, when one looks through the eye-piece, there will appear, many times enlarged, the object at which the telescope is directed.

\section{Graphic Demonstration of Cometary Orbits} By B. C. Batcheller

F XCEPT for those familiar with higher mathema$\mathrm{E}_{\text {tics and physics, it is difficult to understand how a }}$ comet can approach the sun with an ever-increasing speed, sweep around so close to it, and then move away without being drawn into it by the tremendous force of gravitation

The motion of the comet relative to the sun can be illustrated in a simple manner with two permanent inagnets. One magnet may be made of a straight piece of steel wire 8 inches long and $1 / 8$ of an inch diameter, the other of a straight steel rod 6 inches long and $1 / 4$ of an inch diameter-the exact size is not important. Both must be hardened and magnetized as strong as possible. Suspend the longer magnet like a compass needle, by a fine thread tied to the middle, and set it swinging through a wide angle in a horizontal plane by means of the other magnet held in the hand. As the north pole of the suspended magnet swings, say, from left to right, bring the south pole of the shorter magnet, held horizontally in the hand, to a position just beneath the plane in which the suspended magnet is swinging, so that if it continued to swing in that plane, its north pole would pass over the south pole of the magnet held in the hand. If the south pole of the magnet held in the hand is brought too near to the plarie of the swinging magnet, then the two poles will be drawn together. On the other hand, if the south pole of the magnet held in the hand is not brought near enough to the plane of the swinging magnet, then the north pole of the swinging magnet will pass the stationary south pole with only a slight deflection. If the south pole of the magnet held in the hand is brought to just the right distance

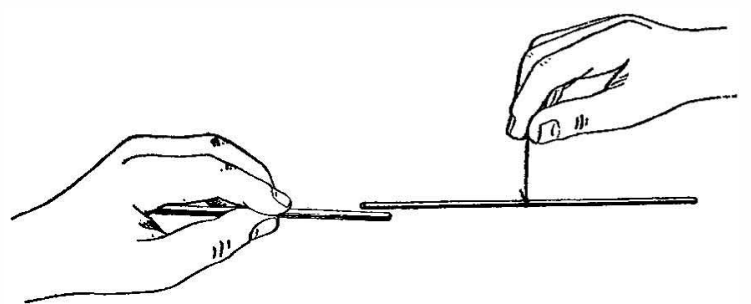

A cometary orbit produced with magnets.

from the plane of the swinging magnet, then the north pole of the swinging magnet will describe an approximate arc of an ellipse around the south pole of the magnet held in the hand, passing quite close to it, magnet held in the hand, passing quite close to it,
but not touching it, as the comet passes around the sun. The pole of the swinging magnet moves with an accelerated speed as it approaches the pole of the stationary magnet, and with a retarded speed as it recedes from it, in accordance with a simliar law to that which accelerates and retards the comet in its path around the sun.

The first few attempts to perform this experiment will probably result in failures, but a little patience is sure to be rewarded with success. I did it the first time by accident, but since then have repeated the experiment many times.

\section{A Modified Form of the Opeidoscope} By C. S. Bourne

$\mathrm{N}$ studying the vibrations of forks or of membranes 1 it is of great interest to the experimenter to make those vibrations optically apparent.

The opeidoscope-so called by Prof A. E. Dolbear, who devised the little apparatus some years ago-provides a simple device for producing that effect. It consists of a tube of tin or paper several inches long, with a membrane of very thin rubber tied over one end, to the center of which is glued a small bit of looking-glass about one-eighth of an inch in diameter. By holding it near the window in such a way as to reflect a small sunbeam to the white wall of the room, and then singing different notes into the open end, the sun spot changes and describes harmonic curves in response to the pitch of the voice and the peculiar vibrations of the membrane. At one pitch it will assume a straight line, again a well-defined ring, then an ellipse, and perhaps a figure 8, varying with the tone of the voice and the movement of the tube.

In experimenting with this simple device, the writer has experienced the same difficulty as others have in being obliged to assume an awkward and strained posture in order to reflect the sunbeam to the desired spot while at the same time holding the the desired spot while at the same time holding the
tube to the mouth. To obviate this, I constructed the tube to the mouth. To obviate this, I constructed the
instrument in the form of the sketch herewith shown, making an elbow. in one tube and providing another slightly smaller, to slip inside, so as to easily rotate

to any angle desired. With this arrangement one may direct the sunbeam with far greater ease than with the single straight tube.

Anyone may make this device with common paper mailing tubes, the parts to form the elbows bein glued at the edges. The instrument is well worth the time spent in making it; and with the window shades drawn to darken the room as much as possi-

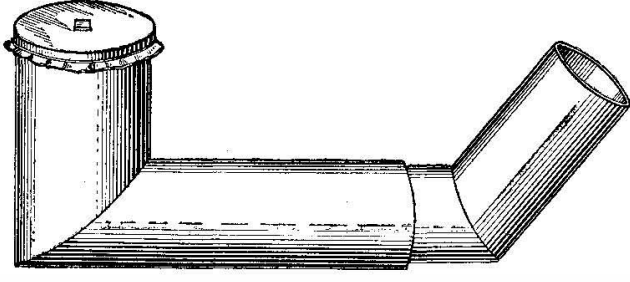

Improved opeidoscope.

ble, it will be found an interesting source of amusement.

In a school room provided with a heliostat, the effect would be enhanced.

\section{An Easily Made Leyden Jar Charger By H. B. Dailey}

ONG before he has acquired the necessary manual ont to build for himself the ectrical enthusiast has at some time or another felt the longing to reproduce for his own benefit at hom some of the fascinating experiments he has seen exhibited in electrostatic physics.

To such it should be interesting to realize that many of the most beautiful and instructive of elementary demonstrations of static electrical phenomena are among those that require only the single charge of a small Leyden jar for their presentation. Physiolog cal effects; the puncturing of refractory materials, an other disruptive manifestations, such as the breakin of tightly corked glass tubes filled with water throug which the discharge is passed; ignition of gunpowder and volatile fluids; momentary illumination of interrupted conductors; chemical union of oxygen and hydrogen in the gas pistol; the ringing of static electri chimes and various other interesting illustrations of electrical attraction and repulsion; simple experiment in Hertuian waves; these are but a few of the pleas ing experimental possibilities of the Leyden jar and its single charge.

The simple arrangement here illustrated will charge a pint size Leyden jar to a high potential in a few moments. The apparatus requires no machine work in its construction and can be built in a few hours wit common tools.

A strip of plate glass $8 \times 33$ inches, with paralle edges is supported at its ends upon shouldered cleat attached to a suitable baseboard, the glass being elevated about $2 \frac{1}{2}$ inches above the board. An amalgam coated, chamois-skin-covered, rubber block adapted to be moved back and forth by hand along the glass, carries a pair of insulated collecting combs which gathe

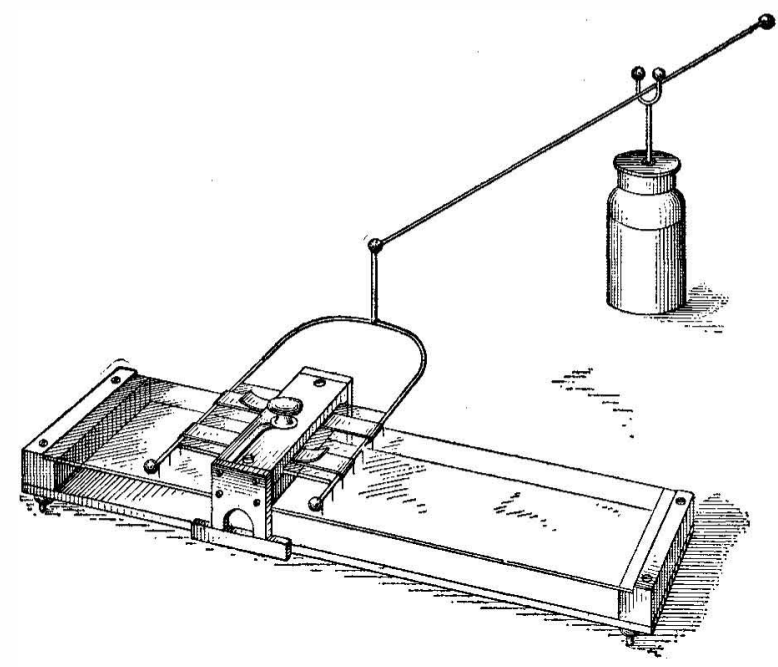

Device for charging Leyden jars

frictional electricity from the glass, transmitting it through an oscillating rod to a Leyden jar standin a short distance to one side of the charger. The body of the rubber block is formed of two superposed piece of soft wood, each $7 / 8$ inches thick and 4 inches wide having a length slightly greater than the width of the glass plate. Thin hardwood guide pieces shap as in the illustration, attached to the ends of the rubber block, guide the movement of the latter by engaging the edges of the baseboard.

The collecting combs are carried by a rectangula insulating strip of plate glass measuring $6 \times 10$ inches which is clamped at its middle across its narrower $\mathrm{d}$ mension between the two halves of the rubber block, the upper half of which is channeled transversely to receive the glass. The collector combs consist of two rows of downwardly directed metallic points reaching nearly to the glass, attached to the under sides of the parallel limbs of a U-shaped loop of stout brass or copper wire, which is bound to the ends of the insulating plate with two or three tightly drawn bands of half-inch silk ribbon.

The points, which are placed about half an inch apart, are made by soldering short common pins by their heads to the collector rods, the rows of points being slightly shorter than the width of the friction glass on which the rubber glides. To keep the combloop from slipping off the ends of the insulating plate small holding clips made from rectangular strips of thin sheet brass, bent into $\mathrm{U}$ form, and measuring before bending $3 / 3 \times 5$ inch, are soldered round the bcdy of the comb-loop at the point where the binding ribbon is to be applied, the ends of the clips extending a very short distance upon the surface of the insulating pjate. Thick shellac varnish is applied to the inner surfaces of the holding clips and the binding ribbon applied over them, after which the insulating plate including the ribbon is well coated witi shellac which renders the attachment permanently firm.

In making the friction pad, two thicknesses of chamois skin exactly the size of the rubber block are laid upon the block's under surface, a piece of tinfoil, of the same size is placed upon these, and a wider piece of chamois skin is drawn tightly over the whole, brought round the edges of the block and fastened with small tacks. The tinfoil within the pad is electrically connected with the hand-knob on the top of the rubber block through a narrow strip of tinfoil shellacked round the end of the block and along its top surface before the guide-pieces are put on. The pad is now charged with a thin coating of friction machine amalgam made adherent to the chamois skin by means of a very'small quantity of lard applied to the rubber. Amalgam from the back of an old mirror answers fairly, but it is much better to buy a small quantity of the regular kind from makers of laboratory supplies.

A 4 -inch piece of $1 / \frac{1}{4}$-inch brass tubing soldered vertically on the bend of the comb-loop carries a slender oscillating rod which extends out horizontally between the ball-tipped prongs of the forked stem of the Leyden jar. The nearer end of the rod terminates in a $3 / 4$-inch metal ball provided with a vertical stem which turns freely in the tubular socket. To prevent the escape of electricity into the air the terminals of the comb-loop, oscillating rod, and jar fork are protected with smooth brass or leaden balls, and all projecting angles, and sharp corners are carefully avoided.

A few movements of the rubber along the glass charges the jar which may then be detached from the apparatus and its charge used in any desired manner.

An excellent Leyden jar for this arrangement can be made as follows: Secure a tall tumbler of thin blown glass and coat it within and without with tinfoil to about half its height, attaching the foil with shellac varnish nearly dried. Put several ounces of fine shot into the tumbler to give it stability.

Stand the forked stem vertically in the shot and pour melted paraffine into the tumbler to within $1 / 4$ inch of the top of the tinfoil coating.

If plate glass is not available for the apparatus double strength window glass is equally effective electrically; but should this be used the friction plate should be supported in several places with vertical pieces of glass tubing let into holes in the baseboard.

Like all machines of the frictional type the present apparatus requires the dry cold weather of winter for its most successful operation. Warming the friction plate and occasionally stirring up the amalgam on the rubber add considerably to the machine's effectiveness.

\section{How Clouds Get Their Fringes}

TYNDALL used to explain to popular audiences, with the aid of a brilliant experiment, that the blue color of the sky is owing to floating particles of in visible dust that break up and scatter the short waves, which are the blue waves, of light. This, as has recently been pointed out, occurs principally at a great elevation, where the atmospheric dust is extremely fine, while in the lower regions of the air, where the dust is coarser, the scattering affects all the rays, or colors, alike. The brilliant fringes of clouds, seen nearly in the direction of the sun, are largely due to dust, which especially accumulates in the neighborhood-of clouds, and refracts the sunlight around their edges.

\section{A Correction}

$T^{H E}$ article on the Unique Wind Vane and Electric Indicator, appearing in our issue of January 21st, 1911, was prepared by Mr. James L. Blackmer, the constructor of the instrument, and not by Mr. Frank C. Perkins. 